\title{
CROSS-LINGUISTIC EVIDENCE AND THE LICENSING OF IMPLICIT ARGUMENTS
}

\author{
GER GELY PETHÖ AND E V A K A R O S \\ University of Debrecen
}

\section{A B S T RACT}

This paper discusses the occurrence and the licensing of implicit object arguments, also referred to in the literature as null complements or understood arguments. Functionalist accounts (such as those by Groefsema and Németh T. which are couched in a relevance-theoretic framework) have repeatedly claimed that this phenomenon is fundamentally dependent on discourse-interpretational factors. In particular, it has been stated that implicit arguments can be used in Hungarian in a rather unrestricted way, and their occurrence is only limited by considerations of interpretability. We argue against both of these positions and try to show that cross-linguistic data can assist in revealing the circular nature and ultimate inadequacy of existing functional accounts of implicit argument licensing.

\section{[1] INTRODUCTION}

This paper discusses the licensing of implicit object arguments, also referred to in the literature as null complements or understood arguments. We will argue that theories which aim to explain this phenomenon exclusively in terms of general pragmatic principles (in particular, relevance) are insufficient. We will try to show that some well-known results of these approaches are conceptually and empirically problematic. Instead, a different perspective on argument omission will be proposed, departing from Iten et al. (2005)'s suggestion according to which more traditional lexical-syntactic explanations need to be combined with semanticpragmatic (interpretational) approaches in order to develop a satisfactory theory of these phenomena.

The structure of this paper is as follows: Section 2 will briefly introduce the notion of implicit arguments and summarise the most important points of Fillmore's lexical-syntactic approach (1986), including the classic distinction between indefinite and definite null complements, already proposed by Fodor and Fodor (1980). Section 3 discusses Groefsema (1995), a paper that tries to explain both the licensing and the interpretation of implicit arguments on the basis of Relevance 
Theory. After identifying some problems connected to this position, we will conclude that Groefsema's view of implicit argument licensing is inadequate. Section 4 first turns to the work of Németh T. (most importantly, 2001), who elaborates on Groefsema's theory and applies it to Hungarian. We will indicate that Németh T.'s strongly interpretational account does not differentiate between several possible motivations for the occurrence of implicit arguments, and accordingly it is at least not sufficiently detailed, perhaps even on the wrong track. Consequently, we will agree with Iten et al. (2005) in that a two-stage model, consisting of a lexicalsyntactic and an interpretational-pragmatic component, is needed instead. In a short case study, in section 5, we will further substantiate the claim that syntactic factors are essential to this issue. This section considers superficially related phenomena like resultative constructions and verb prefixation, and aims to demonstrate why cross-linguistic data have to be taken into account in connection with issues like the topic of this paper. Finally, section 6 concludes our discussion.

[2] THE PHENOMENON OF IMPLICIT ARGUMENTS AND THE LEXICALSYNTACTIC APPROACH

\section{[2.1] Characteristics of implicit arguments}

It is a well-known fact that there are sentences in which, judging by their surface structure, some units of information are missing. We can distinguish between different types of such phenomena which are often referred to as implicit arguments in a broad sense. By way of illustration, let us examine a range of examples:

(1) My bicycle was stolen yesterday.

(2) Come over here!

(3) She wanted to open a shop.

(4) Bill likes but Mary hates ice-cream.

(5) My grandmother taught me how to knit.

(6) I wanted to keep my new job a secret but my mother found out.

Although these examples share the property that a particular argument of a predicate is missing in each of them, they differ significantly and do not form a natural class. They are analysed according to different criteria. Example (1) is a passive construction in which the agent argument is not identified by an explicit phrase. (2) is an imperative sentence that is understood with a second person singular pronominal subject, even though this pronoun does not appear on the surface. (3) is a so-called control structure that contains an infinitival predicate (open) that does not have an explicit subject. Generative syntax commonly assumes that a silent element, called PRO, occupies the subject position of this non-finite verb. PRO, in turn, is controlled by (or is, in other words, co-referential with) the sub- 
ject of the finite verb (i.e. she). In (4) we find what is generally considered an elliptic sentence, in the sense that the object of the first verb likes is deleted from the surface since it is identical with the object of hates. (5) contains (in addition to another control structure) the transitive verb knit, which does not, however, have an explicit object in the sentence. The sentence does not talk about a specific article of clothing being knitted, but rather how the speaker has acquired the ability to knit. Finally, in (6) the phrasal verb found out would normally demand a CP or a PP complement with about as its head. Although this example does not contain either kind of argument explicitly, they can be inferred on the basis of the information conveyed at the beginning of the sentence.

As indicated earlier, these types of construction are not treated in a uniform way in linguistic theory. (1) and (2) are related to morpho-syntax as their description involves reference to the grammatical categories of voice and mood, respectively. The missing elements in (3) and (4) can be treated by reference to syntactic regularities: (4) can be analysed as a result of PF deletion that is triggered by a certain syntactic configuration, whereas the absence of the agent argument in (3) is required due to the fact that English non-finite verbal predicates cannot agree with an explicit nominative subject. In contrast, (5) and (6) are typically not regarded as having to do primarily with syntax, but rather with lexical semantics, argument structure, and discourse/pragmatics.

As we will discuss later, we do not believe that treating all of these phenomena within a single unified theory of implicit arguments is viable. Instead, our main concern will be the phenomena exemplified by (5) and (6), which can be called null complements, understood arguments, or, alternatively, implicit arguments in a stricter sense.

Let us briefly examine what makes implicit arguments special. Arguments are generally defined as expressions that are combined with a predicate to form a proposition. More specifically, each predicate is assumed to have a certain number of free positions which have to be filled by argument expressions. If we apply this to natural languages, it means that "verbs come with a semantic frame" which "specifies the linguistically inherent participants in the process, state, or event that the verb denotes", as Iten et al. $(2005,2)$ put it (and this characterisation can and should be extended to other types of predicates as well, most importantly to adjectives and nouns).

Iten et al. $(2005,3)$ 's example is the transitive verb lock, which ontologically requires both a subject (agent) and an object (patient) argument in the sense that one cannot conceive of a locking event without someone (or something) who is doing the locking and something that is being locked. At the same time, this verb requires both a subject and a direct object complement in a grammatical sense as well (although there are certain syntactically defined constructions that override this requirement, e.g. passive). 
A different type of predicate, one that can be used with an implicit argument, is exemplified by follow. Whereas this verb also has two "linguistically inherent" arguments, namely the follower and the thing being followed, and these are both ontologically required for an event to qualify as a following event, the object argument can be left out under circumstances that cannot be chracterised in strictly grammatical terms, as in:

(7) Tom's already gone out to Rome and his wife and children will follow shortly. (LDOCE 4 CD-ROM: FOLLOW 1.)

The difference between lock and follow is that the latter verb can be used without an explicit direct object provided it becomes clear from the context who is being followed, but the same is not possible for lock under similar conditions. In other words, for follow there seems to be a failure of isomorphism between linguistic levels: the verb's semantics, as per the semantic frame, specifies two linguistically inherent participants for the denoted event/action/process, but in some fully grammatical sentences there is no (overt) constituent in the syntax for one of them (Iten et al. 2005, 3) .

A linguistically inherent argument that is characterised by such a failure of isomorphism in a given sentence (i.e. it is phonologically unrealised but contributes to the meaning of the whole structure) can be called an implicit argument in a narrow sense.

Having introduced the concept of implicit arguments, let us now come to a possible explanation for this phenomenon, which seems reasonable as a first approximation.

\section{[2.2] Fillmore's lexical-syntactic approach}

A classic approach to implicit arguments is the so-called lexical-syntactic approach, which assumes that the ability of a predicate to occur without some of its arguments in a sentence is encoded in the part of its lexical entry that specifies predicate-argument relations. In his (1986) paper, Fillmore stresses that verbs are to be distinguished on the basis of their ability to stand with null complements, such as in the case of lock vs. follow (as mentioned above). One of his own examples was the verb-pair guarantee and promise. He states that despite the similarity of the two verbs' meanings (they both assume the existence of something guaranteed and something promised, respectively), the omission of the object clause is not allowed in the case of guarantee (and similarly for the verbs pledge and vow), whereas it results in grammatically correct sentences with promise.

(8) She guaranteed / pledged / vowed *(that she will take part in the organization of the conference). 
(9) She promised (that she will take part in the organization of the conference).

Fillmore explains the difference between verbs (and predicates in general) that do allow and ones that do not allow null complements by claiming that different argument structures are assigned to them in the lexicon. He states that complements in general are not omissible, so specific verbs that do license implicit arguments have to be provided with a syntactic feature value marking whether a complement can be omitted.

Fillmore further proposes a renowned classification of implicit arguments according to certain parameters. He points out that a distinction is needed between what he calls indefinite null complements (INC) and definite null complements (DNC). ${ }^{1}$ The members of the first group are implicit arguments, the referent of which cannot be identified, or its identity is a matter of indifference (i.e. they are understood as not referring to anything specific, which can be approximated by an existentially quantified variable in semantic representations). INC verbs such as eat, read, write, and drink can occur in structures where the object of the eating, reading, writing or drinking event is not expressed. For instance, in (10) we can infer the presence of a hidden object (that is a liquid substance).

John was drinking.

'John was drinking something that is possible to drink.'

As opposed to the former group, DNC are interpreted as having definite referents (for example, specific discourse referents) that have been mentioned in previous utterance segments.

(11) a. Peter's parents had never got married. I wonder if he knows that.

b. Oh, I think he finally found out [that his parents had never got married $]^{2}$.

(12) a. How come you have submitted your paper a month before the deadline of July 1st?

b. Well, my instructor insisted [that I submit my paper a month before the deadline].

In (11-b) and (12-b) the DNC can be interpreted on the basis of (11-a) and (12-a) because its referent is clearly extractable from context. Similarly to the issue

[1] Fodor and Fodor (1980), among others, had already distinguished between two classes of verbs allowing object omission in a similar way. They claim that the semantic representation of sentences containing a member of the eat-class of verbs involves existential quantification. John ate, for example, entails that John ate something. In contrast, they see notice-class verbs (e.g. watch, join in, approve) as necessarily anaphoric and entailing a definite object: John noticed entails John noticed it and not John noticed something.

[2] Information that is understood but is not uttered explicitly is surrounded by square brackets. 
of omissibility in general, Fillmore assumes that INC versus DNC behaviour of a complement is specified in the lexicon: "the determinants of the omissibility phenomena are lexical in the sense that individual lexical items will simply have to be represented as having certain of their complements marked as indefinite omissible and definite omissible." (Fillmore 1986, 98; italics in the original). He explicitly states that he does not see a viable semantic or pragmatic explanation for the variations in question: "There are certain semantic groupings of predicates that allow the two kinds of complement omission, but a genuine semantic explanation does not appear to be forthcoming. In the case of DNC, no purely pragmatic explanation will help us either" (op. cit. 98).

In other words, Fillmore believes that both the licensing of implicit arguments and the determination of their interpretation are idiosyncratic features of individual lexical items. However, this position is not shared by everyone. A number of authors have pointed out that there are quasi-syntactic conditions in English that license or at least facilitate the omission of complements, like coordination, topicality and contrastive focus among others, cf. Goldberg (2001), Cote (1997), or Velasco and Muñoz (2002). Semantics has also been assumed to play a decisive role in the interpretation of INC versus DNC verbs contrary to Fillmore's position: Sæbø (1996) argues that semantic presuppositions connected to individual verbs enable us to predict whether an implicit argument receives a definite or an indefinite interpretation. Finally, Fillmore's lexical-syntactic approach has also been disputed by authors who have emphasised that pragmatics plays a significant role in licensing implicit arguments, e.g. Groefsema (1995) and Németh T. (2000a, 2001). We will examine the views of these authors in the following two sections.

\section{[3] GROEFSEMA'S SEMANTIC-PRAGMATIC APPROACH}

Groefsema takes a position that is radically different from Fillmore's with respect to both major components of the theory of implicit arguments: 1) the licensing of omission, and 2) the choice of definite versus indefinite interpretation of an omitted element. Firstly, she claims that "arguments can only be left implicit if their interpretation is constrained in particular ways, because the constraints make the interpretation of the implicit argument immediately recoverable. When there is no constraint on the interpretation of an argument, leaving it implicit could lead the addressee to a misinterpretation, and Relevance considerations would rule this out" (Groefsema $(1995,139)$. Secondly, the difference between INC and DNC verbs is that "INC verbs only put a selection restriction on their internal argument as far as the type of THING that is at stake [sic], while DNC verbs specify that an instance of a THING is at stake" (op. cit. 147). For both components of the theory, we will first summarise what arguments Groefsema presents to support her claims and then we will point out some empirical and conceptual problems. 


\section{[3.1] Licensing of implicit arguments in Groefsema (1995)}

Groefsema accounts for the omissibility of arguments on semantic-pragmatic grounds within the framework of Relevance Theory:

A verb can only be used with an understood argument if the interpretation of the argument is constrained in one of two ways. In the first place, an argument can be left implicit if the verb puts a selection restriction on the argument such that it gives us an interpretation in accordance with the principle of relevance (Groefsema 1995, 152).

In the following lexical entry of the verb eat, it is specified that the direct object of the verb is of the type FOOD.

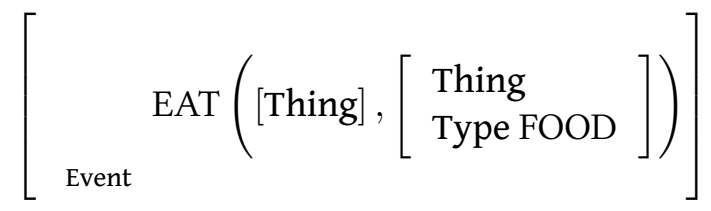

In case this verb is used without an explicit direct object in some context, it can therefore be retrieved from the lexicon that it is some food that is being eaten. Note that the selection restrictions do not mean that the predicate in question cannot occur at all with an object that does not belong to this sort (FOOD); for example, the sentence Sandy has eaten a marble in the sense of 'Sandy has swallowed a marble' is grammatical and acceptable and can be interpreted without difficulty. It is, nevertheless, an instance of loose use in the sense of Carston (2002, Chapter 5). As Németh T. and Bibok $(1999,414)$ observe, implicit objects are regularly interpreted in accordance with such selection restrictions, so these restrictions can apparently function, more generally, as some kind of default condition regarding the content of the verb's arguments. For example, the sentence

(13) Sandy has eaten.

cannot be interpreted as 'Sandy has swallowed a / the marble' but only as 'Sandy has eaten some food / a meal'.

The second part of Groefsema's condition on implicit argument licensing is that "an argument can be left implicit if the rest of the utterance makes immediately accessible an assumption (or assumptions) which gives us an interpretation in accordance with the principle of relevance" (op. cit. 153). Her examples are the following:

(14) Paul gave to Amnesty International.

(15) ? Paul gave to Ann.

(16) I always give books on birthdays. 
In (14) the words give and Amnesty International make immediately accessible the information ("assumption", as Groefsema puts it) that people usually give money to this organisation. In (16), the words give and on birthdays activate our knowledge that one usually gives presents (for instance, books) to other people on their birthdays, and furthermore, that there is a set of people that one usually gives presents to, namely, relatives and friends. This allows us to establish the likely recipients of the books, even though they are not explicitly mentioned. By contrast, in (15) the words give and Ann do not enable us to identify the type of thing that was given. Thus the phenomenon illustrated in (14) and (16) is similar to the previous example in (13) in the sense that information that is not explicitly spelled out in the sentence (because an argument is missing) is inherent in some other information source. In the previous case, this source was the lexical entry of the predicate itself. In this case, it is the immediate context of the predicate within the utterance.

We believe that Groefsema's position on licensing is problematic for several reasons. In connection with simple cases like (13), her assumption is essentially that the stricter selection restrictions apply to a certain argument (i.e. the more information about its possible arguments the verb itself contributes to the sentence), the more likely it is that a relevant interpretation can be achieved without any explicit mention of that argument. Consequently, if selection restrictions are strict enough, an argument of the verb may remain implicit.

Note that Groefsema does not define a clear boundary between cases where information provided by such restrictions is sufficient to license an implicit argument and where this is not the case. It does not become clear why e.g. eat can be used intransitively, as opposed to lock, which requires its object to appear on the syntactic surface, even though its relevant selection restrictions do not seem to be any less specific: eat requires food as its object, whereas lock requires an object that has a lock, e.g. a car or a door.

In addition to this problem, which we consider the most serious difficulty for Groefsema's approach, there are further issues to be noted. We do not think that it is possible to reduce the possibility of the omission of an argument to the availability of a relevant interpretation for the utterance (on the basis of what has been explicitly said and what is known by the language users). Consider the verb read that can be used without an explicit direct object, in which case the implicit argument receives an indefinite interpretation. If we add the adverb aloud to this verb, omission of the direct object becomes far less acceptable. From the point of view of Groefsema, this is unexpected because the set of possible candidates for the referent of the direct object is, if anything, more restricted in the case of read aloud than in that of read (one usually reads aloud a sentence, a passage, a poem, or a short text, but not a novel). 
Furthermore, Iten et al. (2005) have demonstrated that Groefsema's reasoning in connection with (15) is stipulative and ultimately unconvincing:

If 'being optimally relevant' were really the issue, and things beyond selection restrictions and utterance make-up could contribute to relevance, then any context in which the discourse situation made clear enough that money was at issue should, it seems, be one in which 'money' can be omitted from (15). So, we don't get the prediction that (15) is unacceptable unless there is a ban on non-linguistic stuff contributing assumptions when evaluating for optimal relevance. (Iten et al. 2005: 9)

They maintain that it makes no sense to exclude non-linguistic information from optimally relevant interpretation, and this would indeed seem to contradict the essence of pragmatic explanations. We will return to this issue in section 4.4 and suggest that Groefsema's position might be more properly seen as a result of circular reasoning instead of stipulation.

What has been said so far shows that, although there may be more than a grain of truth in Groefsema's picture of the licensing of implicit arguments, it is at the very least incomplete: As it stands, the theory only allows us to predict that if a certain predicate-argument combination has already been used successfully in a certain context (I am eating), it will probably also be acceptable if we use it in another similar context to similar effect. However, on the basis of what Groefsema says in her paper, it is crucially impossible to tell in advance whether I am eating, I have locked, Paul gave to Ann etc. per se are acceptable or not. On the other hand, when her theory does in fact enable us to formulate a prediction, that prediction is often wrong (as in the case of read aloud, or eat versus lock above).

\section{[3.2] Indefinite vs. definite interpretation of implicit arguments in Groefsema (1995)}

Let us now turn to the second component of Groefsema's theory of implicit arguments, namely, her position on INC versus DNC behaviour of verbs. She derives this property from selection restrictions as well. As we have indicated, she claims that "a verb can specify that its argument is of a particular type [or] that it is an instance of a particular type" (op. cit. 146), and that an implicit argument receives an indefinite interpretation if it is marked in the corresponding selection restriction of the verb as a "type", whereas definite (anaphoric) implicit arguments are marked as "instances". Eat as an INC verb specifies that its object has to be a type of food, as we have seen above in section 3.1, whereas win as a DNC verb has an object that is an instance of a competition: 


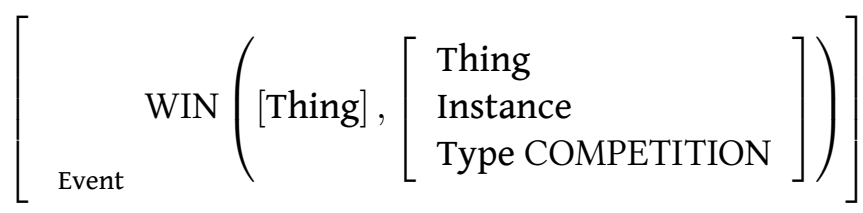

However, it is unclear what Groefsema means by this distinction, since (quite trivially) being of a particular type and being an instance of a particular type are arguably one and the same thing. Sticking by the actual characterisations that Groefsema provides, i.e. claiming that read has a selection restriction that says it takes objects that are types instead of instances, we would expect that read belongs to the class of predicates that do in fact take objects that are names of kinds, very much like invent, become extinct or common:

(17) Bell invented the telephone.

(18) The dodo has become extinct.

(19) The field mouse is a common animal.

Note that in these cases, the object never refers to a specific object (an instance of a type) but to a type as such. Furthermore, these predicates cannot occur with objects that denote specific entities at all, e.g. *Bell invented the telephone in the corner. ${ }^{*} M y$ dog has become extinct. We can, therefore, conclude that these verbs do have the exact same selection restriction that Groefsema proposes for INC verbs like eat, drink and read, which, unfortunately for her, do not behave like this at all (even allowing that we can regard selection restrictions as default conditions, like in the case of eat taking an object that is food). She must have something different in mind instead of the distinction between "type" and "instance" proper, but since she does not provide any further explanation for her dichotomy, it is unclear how it could be rephrased in a more coherent way.

Assuming that the above distinction does indeed make sense, it still seems that Groefsema's characterisation of specific verbs makes incorrect predictions about their distributions in sentences where they do in fact occur with an explicit argument. Although it is uncertain by what kind of complement the selection restrictions "type" and "instance" would exactly be satisfied, one could reasonably assume that this distinction is related to some well-known linguistic semantic dichotomy, e.g. genericity vs. specificity. Thus, read being a verb that takes, according to Groefsema, an object that is of type 'symbolic representation' (but not an instance of this type), one could assume that this predicts that read may only (or at least typically) take objects that are bare plurals or mass nouns (20) but not NPs referring to specific entities (21).

(20) I am reading newspapers. 
(21) I was just reading that brown book over there.

On the other hand, win, being a verb that demands an object that is an instance of a type, should only appear with specific NP objects (22) but not with bare plurals (23).

(22) She has won the race.

(23) They play really smart ball and they often win championships. (LDOCE 4 CD-ROM: examples bank for wIN)

It is not only this pattern that could plausibly be assumed to be predicted by Groefsema's selection restrictions but fails to apply. In fact, we cannot find any other clear distributional differences between INC and DNC verbs in general, either, when their relevant arguments are explicitly expressed. Thus it would seem that what Groefsema has stated are not really selection restrictions at all, but simply a description of the fact that some implicit arguments receive a definite or indefinite interpretation, i.e. nothing that would further illuminate the issue. In other words, it seems that Groefsema's position is in fact identical to Fillmore's lexical theory that she attacks, with the sole difference that she (mistakenly) characterises Fillmore's features definite and indefinite omissible as selection restrictions and calls them, somewhat confusingly, 'instance' and 'type' (instead of definite/indefinite or specific/non-specific).

[4] TOWARDS A TWO-STAGE MODEL OF IMPLICIT ARGUMENT LICENSING

\section{[4.1] An outline of a general interpretational theory}

In the previous section we summarised an approach that accounted for the licensing of implicit arguments on semantic-pragmatic grounds. We can also find a number of further attempts to explain the phenomenon in question from a related, more or less functional perspective. For example, Goldberg (2001) concentrates on the omissibility of direct object arguments. The essential claim of her paper is that an object argument can be omitted whenever it is not at the centre of attention. More specifically, "omission is possible when the patient argument is not topical (or focal) in the discourse, and the action is particularly emphasized (via repetition, strong affective stance, discourse topicality, contrastive focus, etc.)" (Goldberg 2001, 514).

Instead of trying to survey functionalist work on the issue extensively, we will concentrate, in the following, on one author who takes a very distinctive stand with respect to our subject. We assume that the problems that we will indicate (and that have in part already been mentioned in the previous section) apply, mutatis mutandis, to all approaches to implicit arguments that try to reduce licensing of omission to the aspect of interpretability. 
Németh T. (2000a, 2001, see also Németh T. and Bibok 1999, and Bibok and Németh T. 2001) examines Hungarian verbs and claims that these "verbs do not vary as to whether they can occur with implicit arguments, but they vary as to in what manner and in what context they can occur with such arguments" (Németh T. and Bibok 1999, 412). She states that there are three ways in which complements can be left out of a sentence:

(i) if some part of the conceptual semantic representation of a verb - including a selection restriction or a prototypical structure of a category or a lexical stereotype or a presupposition - makes it possible to recover the implicit argument in accordance with the principle of relevance; (ii) if the rest of the utterance in which the argument occurs makes an assumption with the typical interpretation immediately accessible in accordance with the principle of relevance; and (iii) if extending the immediate context of the argument leads to an interpretation consistent with the principle of relevance (Németh $\mathrm{T}$. 2001, 152).

Her options (i) and (ii), taken together, are essentially the same as Groefsema's condition on the omissibility of arguments. (i) explains omission in cases such as (13) above, and (ii) accounts for examples like (14). The motivation for (iii) is exemplified in (24) (taken from Németh T., 2001: 147) and (25) below.

(24) (The interviewee is speaking about her relationship with her younger brother in their childhood.)

- Nem voltál rá mérges néha, hogy te most nem

mehetsz oda, ahova akarsz, mert az öcsédre kell vigyáznod?

'Weren't you angry with him sometimes for not being able to go where you wanted to, because you had to take care of your younger brother?'

Dehogynem. Dehogynem. SOKSzOR ELŐFORDUL-T [ ]

yes-of-course yes-of-course often occur-PAST.INDEF.3SG

ÉS MEg IS SZOK-T-AM VER-NI ÉRTE [ ].

and PFX also use-to-PAST-1SG beat-INF for-it

'Yes, of course, of course. It happened many times and I used to beat him for this.'

In the first half of the highlighted sentence, literally 'occurred many times', the argument that specifies the event that occurred is missing. This is possible because that information has already been mentioned in this context, namely in the first sentence: 'you were angry with him because ...'. In the second half, literally 'used to beat for this', two arguments are left out of the sentence, namely, the first 
person singular subject, and the third person singular object. Although Németh T. does not discuss this, it is the grammar of Hungarian that is ultimately responsible for the possibility of omission of these arguments in the case of both predicates: Hungarian verb inflection clearly marks number and person of the subject and in large parts of the paradigm definiteness or indefiniteness of the direct object by agreement morphemes. For example, the ending of eloffordult 'occurred' shows that the subject is third person singular. ${ }^{3}$ Context plays a role insofar as the verbal inflection (together with the rules of Hungarian pro-drop) only reveals that both the subject of eloffordul and the object of megver 'beat' is third person singular. The actual reference (in a broad sense) of these missing arguments is established by pragmatics. More specifically, what enables us to achieve a relevant interpretation is the linguistic context (preceding discourse), as explained above.

Furthermore, the elements of the situation and encyclopaedic knowledge may also contribute to the creation of a relevant interpretation, as in the following example (Németh T. 2000b, 201):

(A mother is strolling along with her children. One child is sitting in a baby carriage, while the other one, Áron, is walking next to the carriage. "I'll step back to the nurse", says the mother to the kids; the baby starts crying.)

The mother comforts her child:

"Ne sír-j, Áron tologat [ ]."

Not cry-IMPER.2SG, Áron push.INDEF.3SG

'Don't cry, Áron will push you.'

In this case the subject of the verb tologat is expressed (Áron) but its object is missing. From the inflectional suffix of the verb form, namely, the suffix that expresses indefinite object agreement, we can only tell that the implicit object must be either first or second person singular or indefinite third person singular ('something'). On the basis of the situation (the speaker, the hearer, and other people present) and world knowledge (people usually push babies in carriages and this way they comfort them) we can infer that it is not the mother (first person singular) or an indefinite third person singular (something) that is being pushed, but rather the baby that is the addressee of the utterance (second person singu-

[3] The Hungarian verbal paradigm consists of two sub-paradigms: one is typically used when the verb has an indefinite direct object, whereas the other is used if there is a definite direct object. The indefinite subparadigm is "unmarked" in the sense that it is chosen not only when the verb actually has an indefinite third person direct object, but rather as a default case. This means that all intransitive verbs (which, of course, do not take an object at all) as well as verbs with first and second person direct objects (which are not, strictly speaking, indefinite) appear with indefinite object agreement morphemes as well. For example, the form eloffordult in (24) is intransitive and accordingly contains the suffix characteristic of the indefinite sub-paradigm. On the other hand, the definite sub-paradigm is only used when the direct object is third person (singular/plural). 
lar).

Németh T. stresses that "verbs can occur with implicit arguments far more freely in Hungarian than in English" and other languages (Németh T. 2001, 113). By this she presumably means that if a sentence can occur with an implicit argument in a certain context in one language, it is possible that in another language where the occurrence of implicit arguments is less free, the equivalent sentence will be unacceptable / ungrammatical. In another paper she adds the following: "in Hungarian, verbs do not vary as to whether they can be used with implicit arguments or not as they do in English and in languages similar to English, but they vary as to in what manner or in what context they can occur with such arguments" (Németh T. and Bibok 1999, 425). This claim is central to Németh T.'s view and therefore deserves attention. Her formulation would suggest that basically everything is possible in Hungarian with respect to argument omission, which would make this language similar to East-Asian languages that are considered to be extremely "free" in this respect.

However, this latter conclusion is incorrect. It only arises because one important consideration is missing from Németh T.'s account: she does not specify what licensing factors underlie the omission of arguments but instead analyses particular examples from the perspective of interpretation, without examining their grammatical characteristics.

If we take into account the aspect of grammar as well, however, we get a more complex picture, according to which Hungarian is not all that different from English. In other words, if we exclude the phenomena of ellipsis (like (4)) and prodrop ${ }^{4}$ in Hungarian, we realise that similarly to English, some verbs do whereas others do not allow object omission. This applies both to 'direct' (accusative) and to 'indirect' (otherwise marked) objects, as in (26) and (27), respectively:

$$
\begin{aligned}
& \text { János fogott. } \\
& \text { 'John held/caught.' }
\end{aligned}
$$

Example (26), with an indefinite inflection form of the transitive verb fog 'hold/ catch', is not interpretable and is unacceptable unless a pro-drop interpretation with a first person singular object ('John held me') is forced.

$$
\text { 'János hozzáfogott. }
$$

Example (27) contains the verb hozzáfog which takes an indirect object with the

[4] The phenomenon of pro-drop in Hungarian is an intricate system, which we will not explain here for the lack of space. We can only note that Hungarian object pro-drop is interconnected with the definiteness agreement of Hungarian verbal inflection that was briefly outlined in the previous footnote. The reader is advised to consult any good descriptive grammar of Hungarian for a more thorough description of the system. 
case-ending -hoz, i.e. is not strictly speaking transitive. Object pro-drop only applies to direct (accusative-marked) objects in Hungarian, so it is no option in this case. The verb normally requires an explicit indirect object, so the sentence is ungrammatical unless it is parsed as an elliptic construction that requires an appropriate indirect object to be understood on the basis of the immediate context.

We can conclude that Németh T. can only maintain her claim that Hungarian is significantly more "free" compared to English with respect to argument omission if her theory does not distinguish between different sources of omission (ellipsis, pro-drop, and others). If we do take these issues into account, the contrast in question between these two languages has rather little to do with pragmatics, but boils down essentially to differences between their grammars: most importantly the fact that one is a pro-drop language but the other is not; and also to divergent rules of ellipsis (which presumably follow from more abstract parametric variation with respect to sentence structures).

To sum up: we believe that treating all kinds of argument omission as a common, unified phenomenon is not the right way to proceed. Claiming that every Hungarian verb can occur with an implicit object is, in a way, correct. But this would be akin to claiming that the same holds for every English verb, too, since verbs that normally require an object, e.g. lock, like etc., are allowed to occur without one in right node raising structures (cf. Postal 1974) like (4). Németh T.'s strategy is to take structures where, contrary to English, Hungarian allows argument omission, and show that the way Hungarian behaves is "reasonable" from a Relevance Theory perspective. We believe that looking for the reasons why these cross-linguistic differences occur would lead to deeper insights. Presumably, in many cases the outcome of this search would be a collection of language-specific regularities that are, strictly speaking, syntactic, and that can be defined much more precisely than the vague "freeness of argument omission" parameter that is often referred to in the relevant literature.

\section{[4.2] An alternative: a two-stage model of implicit argument licensing}

To continue the previous point, we will argue that an account of implicit argument licensing with a significantly higher explanatory power could be attained if we chose a more differentiated theoretical framework. One such general framework was proposed by Iten et al. (2005). After pointing out some deficiencies of Groefsema (1995), the authors conclude that an exclusively interpretational theory of implicit argument licensing is inadequate. We can call a theory of licensing 'interpretational' if it claims or implies, like the approaches of Groefsema (1995) and Németh T., that argument omission is allowed if and only if the sentence containing a null complement can be interpreted (namely, by relying on word meaning, linguistic and non-linguistic context, and world knowledge). 
Iten et al. (2005) argue that an adequate explanation of licensing will have to acknowledge the role of language-specific syntactic rules and word-specific idiosyncrasies as factors equally important to general considerations of interpretability. They state that the question 'what licenses null complements?' can be read in two ways.

It can be taken to be a question about expression types, i.e., about what the grammar does (or does not) generate. Call this Q(A). Alternatively, it can be read as a question about which in-context utterances are acceptable/felicitous. Call this $\mathrm{Q}(\mathrm{B})$. Put otherwise, $\mathrm{Q}(\mathrm{A})$ is about which verbs (or verb senses) allow null complements, and of which kind, as a matter of their context-invariant grammar (Iten et al. 2005, 10; emphasis as in the original).

$\mathrm{Q}(\mathrm{B})$, on the other hand, enquires under what contextual conditions a speaker may use a null complement provided that the sentence is generated by grammar. Accordingly, we can assume a two-stage model of language use that consists of a first stage of pure syntax, which decides whether a structure is grammatical or ungrammatical, and a second stage of interpretation, which decides whether the utterance makes sense (is acceptable) in a certain context. If a structure is not generated by grammar, it might still be interpretable and even occur in everyday language use (as a performance error, which might be so frequent that it can become lexicalised eventually as an idiomatic phrase) but it is clearly ungrammatical, e.g.: *Do you like? in the sense of 'Do you like this?'. On the other hand, if a structure is generated, its acceptability in a particular context will depend on whether it is interpretable.

Let us illustrate why we need both components of this system and how the two stages are related to each other. Firstly, we examine the English verb insist, which is a typical DNC verb: it allows its object complement to be omitted, and if omission indeed takes place, the missing argument is interpreted as definite/anaphoric. In other words, this verb can occur with an implicit object in contexts like (28), taken from Fillmore $(1986,98)$ :

$$
\begin{aligned}
& \text { "Why did you marry her?" } \\
& \text { "Because mother insisted." }
\end{aligned}
$$

In this case, grammar generates the structure (it is grammatical) and interpretation is straightforward on the basis of the preceding sentence (it is pragmatically acceptable). Let us contrast this with a second example, which should be interpretable but is strongly ungrammatical.

$$
\begin{aligned}
& \text { "Why did you marry John?" } \\
& \text { *"Because mother wanted." }
\end{aligned}
$$


This example shows why it is necessary to have a grammatical component in our theory of licensing: if context (28) allows for the object of insist to be omitted, the same should be possible in (28)'s minimal pair (29), which only differs from the former with respect to the choice of the verb. Since the context is identical, there are only two possible explanations for the difference of acceptability between the two examples (we exclude interpretational options along the lines of Groefsema (1995), as we should on the grounds of what has been said in section 3): Either the lexical entries of the two verbs specify that the first is a DNC verb, whereas the second must not omit its object, or the syntax of English tells us in general that finite clauses and indirect objects (like the object clause or the on-PP complement of insist) may, but non-finite clauses and direct objects (which occur with want) must not be omitted. At this point, we will not address the question which of these options is the correct one, but we can at least state that one of them seems logically necessary.

Finally, let us see an example which shows that we cannot do without a pragmatic component of our theory of licensing, either.

$$
\begin{aligned}
& \text { "Are you coming to the party today?" } \\
& \text { \# "No, mother insisted." }
\end{aligned}
$$

Since (28) is perfect, we can infer that the sentence 'Mother insisted.' is generated as such by grammar. However, its occurrence is restricted to contexts where it becomes clear what mother insists on. Since this is not the case in (30), the answer is pragmatically unacceptable, even though it is grammatical.

To conclude our introduction of the two-stage model, let us briefly consider the status of its notions of grammaticality and acceptability. If language use were "ideal", we would only produce utterances that are both grammatical and acceptable. However, we know that this is not always the case. As a result of what is generally known as performance errors, we do use sentences that should not be generated by grammar. On the other hand, as a result of an inadequate estimation of the context we also produce utterances that are unintelligible for the interlocutors and are therefore pragmatically unacceptable. Nevertheless, we have no choice but to assume that language use is mostly acceptable and grammatical and that we can at least consciously judge whether a given utterance is problematic in some respect.

\section{[4.3] Signs of circularity in interpretational theories}

We believe that the problems noted by Iten et al. (2005) in connection with Groefsema (1995) can be stated on a higher level of abstraction as well. Interpretational (or we could also call them functional) explanations of implicit argument licensing seem very plausible. After all, we are indeed able to interpret acceptable sentences with implicit arguments and do indeed have trouble making sense 
of unacceptable ones. As a consequence, it is a straightforward choice to regard interpretability or, put more generally, ease of interpretation as a decisive condition on omissibility. However, this begs the question whether this condition is just necessary or indeed sufficient as well. Although the advocates of the interpretational approach do not address this issue, they obviously assume that interpretability is indeed a sufficient condition of omissibility. (Note that this may be regarded by some as a general problem for functionalist approaches in linguistics as a whole.) This assumption, i.e. that we only have to consider a single factor when deciding whether an argument is omissible, ultimately gives rise to circular reasoning, as is observable in the papers we have cited. Let us illustrate this by three typical examples.

Example 1: Groefsema $(1995,140)$ mentions that, according to Fillmore, argument omission cannot be given a semantic explanation because "semantically related groups of verbs do not display the same behaviour regarding whether or not they allow understood arguments." Cf. She found out versus * She discovered; I am waiting versus *I am awaiting; I tried versus *I attempted; insist versus require etc. Groefsema does not accept Fillmore's position because "he does not show in what way these verbs are semantically related" (Groefsema 1995, 144) and furthermore she assumes, without explicitly arguing for her decision, that the meanings of these verbs are indeed significantly different from one another. Obviously, it is no wonder that Fillmore does not go out of his way to prove the semantic similarity of these verbs because they are, in fact, relatively closely synonymous: they can be freely exchanged within appropriate contexts, contribute the same truth conditions to sentences uttered in the same context, can be paraphrased in roughly the same way, etc. The only conceivable reason for claiming that they are semantically not related would be the consideration that they absolutely have to be semantically different in case they behave differently with regard to argument omission. In other words, the reasoning goes: "Why is it that find out occurs with a DNC and discover does not? Because they are semantically unrelated. How do we know that they are semantically unrelated? Because find out occurs with a DNC but discover does not."

Example 2: This is mentioned in Iten et al. $(2005,9)$ as Groefsema's Dictum. It can be illustrated by our examples (14) and (15), repeated below:

(14) Paul gave to Amnesty International.

(15) ?Paul gave to Ann.

The question is: following Groefsema's relevance theoretic view, why is (15) less acceptable than (14), even in contexts that make it clear what Paul was going to give to Ann. Note further that Paul gave it to Ann would be the preferred way of conveying the message in question, which only differs from (15) in that it con- 
tains a semantically quite empty but explicit pronominal it. Groefsema is forced to answer: "Relying on non-linguistic context inevitably leads to unnecessary processing effort, so that the resulting utterance will not be optimally relevant" (Iten et al. 2005, 9; emphasis as in the original). Now how do we know that it leads to unnecessary processing effort? Because (15) is less acceptable than (14) or the same sentence with an explicit pronominal. Again, the argumentation is viciously circular.

Example 3: We have mentioned above that Groefsema $(1995,146-147)$ tries to explain the difference between INC and DNC verbs by claiming that different selection restrictions are assigned to their relevant arguments. But how do we know that the selection restrictions assigned to these arguments are different? As we have pointed out, this question would normally be answered by enumerating distributional limitations of the verbs in question (i.e. what kinds of argument they can co-occur with). However, Groefsema does not mention such limitations and it is questionable whether there are any at all. Therefore, we can assume that Groefsema's answer would be: they must be different because some of the arguments are DNC and others are INC, and there must be a lexical-semantic explanation for this.

We believe that the appearance of such examples of circular reasoning in Groefsema (1995) is only an indication of a more fundamental conceptual problem: exactly because of their apparent plausibility, purely functional explanations for implicit argument licensing are prone to be circular, or, in other words, be no more than pseudo-explanations. The best way to avoid this is to compare, in several languages, otherwise equivalent structures that differ with respect to the possibility of argument omission.

\section{[4.4] Cross-linguistic differences and similarities}

It has been stated several times in the literature (as early as Fillmore 1986) that a purely functional approach to implicit arguments is not viable, especially when we take into account differences between languages. Let us see a few examples to illustrate this point.

Groefsema $(1995,155)$ claims that $(15)$ above is bad because it is not optimally relevant without an explicit pronoun. However, relevance is a pragmatic notion that is essentially not language specific, but a universal cognitive category. Therefore, if a structure without a pronoun violates the principle of relevance in one language, it follows that it must be equally problematic in another language. Arguably, this is not the case. For example, the following sentence (31) in Hungarian would be grammatical, even though it does not contain an explicit pronoun.

(31) Pál Annának adta (?\#AZt).

Paul Ann-to gave (it-ACC).

'Paul gave it to Ann.' 
In Hungarian the anaphoric pronoun azt is grammatical in a sentence like (31), but in most contexts e.g. an answer to a question like "What did Paul do with the money?' it would be completely unacceptable, and even in narrative texts, where the pronoun is allowed to appear, its omission is mostly preferred. However, this apparent difference between Hungarian and English is in some sense only superficial. Sentence (31) contains a definite object agreement verb form adta, and this inflection is basically identical in function to the explicit anaphoric pronominal $i t$. Therefore, we could claim with Groefsema that in whatever way the pronoun contributes to optimal relevance in an English sentence, verbal inflection plays the same role in its Hungarian equivalent. So there is no necessary theoretically relevant difference between (15) and (31). The same cannot be said, however, about examples from other languages such as Southern Cone Spanish mentioned in (Iten et al. 2005), where the morpho-syntactic features of the sentence do not help the hearer recover the missing object, like in (32) (taken from op. cit. 15):

Ya puse para vos.
Already put-1ST.SING for you
'I already put for you.'

We can see that Groefsema's theory predicts that (32) should be just as unacceptable as (15), which is wrong. We can again conclude that a universal pragmatic theory is not the correct way to account for the licensing of implicit arguments, but we need language specific grammars to achieve this goal.

There is another way as well in which cross-linguistic evidence can play an important role in rejecting a purely functional view. There are certain similarities between languages with respect to implicit arguments for which an interpretational explanation does not suggest itself.

This line of reasoning goes as follows: Let us assume that there is, within the same language, a contrast regarding argument omissibility between two structures, which seems to be their particular idiosyncratic property. When arguing for his lexical-syntactic approach, Fillmore (1986) mentions quite a few such contrasts, for example, I am waiting versus *I am awaiting. It would seem that the only way to account for this and similar cases would be to state in the lexicon that the oblique object of wait is omissible, whereas the direct object of await is required. In other words, there is no obvious semantic difference between the two verbs and no obvious grammatical rule, either, by which this contrast could be deduced. Consider an apparently unrelated phenomenon as well: There is a difference between the behaviour of a particular verb in a resultative construction, on the one hand, and in various other syntactic environments, on the other hand, in that verbs never allow the omission of a direct object in a resultative structure John painted *(the door) white, even if they can be used with an implicit INC object in a non-resultative sentence, e.g. wash, paint. Again, it would not be entirely 
trivial to find an interpretational explanation for this behaviour of resultatives and it would at the very least be logically possible that it is an idiosyncratic property of this particular English construction that direct objects must appear in it. However, we cannot exclude the possibility that these phenomena only appear idiosyncratic because we are looking at a single language and do not have a basis of comparison. We believe that this is exactly the case. If we consider other languages in addition to English, we will find that a) prefixed verbs in general tend to require their direct object to be explicit and b) resultative constructions are always obligatorily transitive in any language. Assuming that these generalizations are correct and that they cannot be explained by reference to the relative interpretability of the structures in question, they must have some kind of grammatical explanation. In other words, a theory of implicit argument licensing should not be exclusively based on functional principles, but must have a grammatical component that is in part universal. We will explore this idea in more detail in the next section.

\section{[5] A CASE STUdy: SECONDARY PREDICATION, VERB PREFixation, RESULTATIVES AND ARGUMENT OMISSION}

We have mentioned in the previous section the well-known generalisation (stated for example in Tenny (1994)) that transitive verbs that would otherwise allow an intransitive use (e.g. paint) cannot omit their internal argument in a resultative construction. A similar restriction seems to apply to resultatives and purportedly similar structures (e.g. prefixed and particle verbs) cross-linguistically, in unrelated languages like Hungarian as well.

$$
\begin{aligned}
& \text { János pirosra festett } \quad * \text { (egy kerítést })^{5} \text {. } \\
& \text { John red-RESULT. painted-INDEF. a } \text { fence-ACC. }^{\text {'John painted *(a fence) red.' }}
\end{aligned}
$$

A syntactic-semantic explanation could be attempted for this characteristic property of resultatives, namely, by stipulating a principle that secondary predication, like the one present in resultatives, requires the argument predicated about to appear explicitly. By contrast, an interpretational (semantic-pragmatic) explanation does not seem to be feasible; note e.g. that the resultative construction's inability to appear with an implicit object is not influenced by context (especially salience of an eligible patient in context) at all, e.g.:

[5] This sentence contains the indefinite object agreement form of the verb fest 'paint', which would be fine in a non-resultative structure with an omitted INC object like János festett 'John painted'. Note that inserting the definite object agreement form of the same verb instead, festette, would render (33) perfectly grammatical, since that would be a pro-drop structure equivalent to the English sentence 'John painted it red.' 
(34) *János egész délután a fürdőszobában volt, és pirosra festett.

$\neq$ 'John spent the whole afternoon in the bathroom and painted [it / something] red.'

Similar differences between different occurrences of the same verb can be observed in other cases that can be argued to relate to secondary predication as well, namely, particle verbs in certain languages. The particle, which may predicate a result state of the internal argument, forces that argument to occur explicitly, even if it could remain implicit otherwise, e.g. German and Hungarian:

(35) Sie näht für ihre Kinder. (DUW 4: NÄHEN 1.)

she sews for her children

'She sews for her children.'

(36) Wir nähen *(die kleinen Stoffstücke) zusammen.

we sew the small pieces-of-fabric together.

'We sew *(the small pieces of fabric) together.' (based on COSMAS)

(37) Kati írt délután.

Kati wrote afternoon

'Kati wrote in the afternoon.'

Kati kiírt *(három kérdést) a könyvből.

Kati out-wrote three questions-acc the book-from

'Kati copied *(three questions) out of the book.'

As is well-known, these changes in argument structure correlate with a shift in the aspectual properties of the verbal predicate, i.e. whereas the relevant simple verbs are of the event type 'process' ('activity'), the resultatives and verbs complemented by similar secondary predicates are 'accomplishments'/'achievements' (cf. Rothstein 2004, Chapter 5). In other words, whereas no clear relationship between the role of context and the possibility of argument omission could be observed in these cases, there is in fact a connection between event structure and argument omission, which indicates that both phenomena belong to the syntaxsemantics interface.

The assignment of accusative case by the verb (i.e. a typical grammatical argument structure phenomenon) is another property which is connected to resultatives and prefixed verbs. In the case of resultatives, an otherwise intransitive verb can become transitive (more specifically, reflexive; compare e.g. Müller (2002, 213-215)), e.g. She would cry herself to sleep at night. The same is true for many particle verbs which can also be argued to involve secondary predication, e.g. German herausschreien 'cry out'. 
(39) Er schrie seine Freude heraus.

he screamed his happiness out

'He cried out with joy.'

Similarly to the cases (36) and (38) above, the omission of the object leads to ungrammaticality.

Considering the examples mentioned so far, it may seem plausible to suggest, along the lines of the semantic-pragmatic approach, that what necessitates the appearance of explicit arguments with secondary predication and related phenomena does in fact have something to do with the possibility of reaching a relevant interpretation. One could claim, for example that in the absence of an explicit argument expression, we would not be able to make sense of a secondary predicate.

However, on further scrutiny this reasoning does not seem to be correct. Note that prefixation of verbs leads to the observed effect, i.e. transitivisation and the impossibility of argument omission, even in cases where the prefix quite clearly does not predicate anything about the internal argument in question. This observation can be made with respect to several languages as well. In the following examples (German prefixed verbs with be-), the simplex verb has both a transitive and an intransitive use (in other words, an optional, omissible argument), whereas its prefixed version may only be used transitively (both taken from COSMAS).

(40) Heute bekocht er nur noch seine Familie und Freunde. today PFX-cooks he only still his family and friends 'Today, he does not cook for anybody anymore except his family and friends.'

(41) Der Schienenbus befährt die Strecke am Sonntag dreimal in the rail-bus PFX-drives the distance on-the Sunday three-times in beide Richtungen.

both directions

'The train travels this distance every Sunday three times in both directions.'

Similarly, in Hungarian:
János eszik
(egy almát). vs. János megeszik
*(egy almát).
John eats.INDEF an apple vs. John PFX-eats-INDEF an apple 'John is eating an apple.'
'John is eating an apple.'

In these cases, the simplex verb is lexically imperfective (that is, of the event type 'process'), the prefixed one is lexically perfective (an accomplishment). In neither 
of these examples can we account for the required appearance of the object by the tentative interpretational explanation we have proposed above, since these prefixes do not express secondary predication in a strict sense ${ }^{6}$. Instead the effect of the verbal prefix in such cases is simply transitivisation (along with argument structure modification) and perfectivisation.

Thus far, we have considered verbs from languages that have an extensive productive system of verb formation by prefixation. However, the same observation can be made in connection with English as well. We have mentioned earlier the fact that despite being closely synonymous, wait and await differ in their ability to occur with an implicit object. Such examples are problematic for the interpretational approach since that would predict that two synonymous predicates should behave identically with respect to argument omission. We have also mentioned that these differences appear to be idiosyncratic. However, this can be slightly revised here considering the preceding discussion. For note that there is also a clear difference between the argument structures of these verbs (wait takes an oblique object, whereas await takes a direct object) in parallel with the possibility of intransitive use. Similarly to the cross-linguistic tendency we have already referred to, this correspondence between transitivisation and the impossibility of argument omission appears to a lesser degree in English as well. English prefixed verbs with $a$-, be- and en- are regularly obligatorily transitive, regardless of the lexical category of the base word of the prefixation (i.e. noun, verb or adjective), cf. typical examples derived from verbs: belabour, bescribble, besmear, entrust, arch. bepaint, berob etc.and their simplex versions.

(43) For years, parents and teachers have bemoaned the fact that we do not have a national childcare policy.

(LDOCE 4 CD-ROM: examples bank for BEMOAN)

(44) I'm fed up with hearing you moaning the whole time.

(LDOCE 4 CD-ROM: examples bank for MOAN)

We have to stress that this phenomenon is not productive in present-day English. Instead, these forms are the remnants of a formerly existing rule of English grammar, namely verb transitivisation by prefixation. We also need to add that in German and in Hungarian, where the morphological process is indeed productive, there is no clear dichotomy between prefixed and non-prefixed verbs in the sense that all and only those verbs that are prefixed should be transitive, perfective, and unable to occur with an implicit object, whereas non-prefixed verbs

[6] Note that whereas this claim seems highly plausible to us, there are authors (notably, Kiss 2006) who would claim, on theoretical grounds, that even prefixes like the apparently semantically empty meg or verb modifiers in idiomatic complex verbs are secondary predicates (e.g. the formal object in the idiom csütörtököt mond 'fail', literally 'say Thursday'; or the goal adverbial in fübe harap 'die', literally 'bite into grass'). 
should be intransitive, imperfective, and object-omitting. Still, there is a large number of verb-pairs that exhibit this behaviour, which demands a grammatical explanation. Because there is no obvious functional grammatical explanation, we can assume that we need to account for these phenomena in the syntax-semantics interface of a formalist, universal grammar.

\section{[6] CONCLUSIONS AND OPEN ISSUES}

We hope to have demonstrated some of the shortcomings of interpretational (semantic-pragmatic) theories of implicit arguments. In particular, we tried to make the case that the licensing of such arguments cannot be explained by a theory which exclusively relies on the notion of ease of interpretability (or, in other words, optimal relevance), because such an approach runs into serious conceptual and empirical problems, especially when cross-linguistic evidence is considered. Whereas a semantic-pragmatic approach apparently makes very reasonable claims about implicit arguments, certain differences and similarities between data from different languages indicate that under closer scrutiny, it is grammatical (especially syntactic) regularities rather than interpretability or pragmatics that probably constitute the most important factor of the licensing process. Accordingly, we claimed that a two-stage model of licensing (consisting of a grammar and a pragmatics/interpretation component) promises more adequate explanations for the phenomena in question.

At the same time, we have to admit that what we have done in this paper is no more than pointing out some shortcomings of existing approaches and giving a very vague outline of an alternative position. In particular, it should be clear that the two-stage model of licensing that we have sketched is not, by any measure, a proper theory of implicit arguments, but rather a research strategy or a general attitude toward the description and explanation of the relevant phenomena. In order to turn it into a theory that can be debated, it should be decided exactly what kind of grammar underlies the first stage, and what the pragmatic/interpretational regularities are that make up the second stage. This will have to be filled in by future research.

As a closing thought, let us mention some of our reservations about the picture that Iten et al. (2005) suggest about the relationship of the two subsystems responsible for licensing. We have mentioned that they assume that interpretability decides about acceptability if the structure in question is generated by grammar. However, consider examples like (45), which is very similar to (28) in section 4.2:

$$
\begin{aligned}
& \text { "Are you coming to the party today?" } \\
& \text { \#"No, because I have work to do and mother insisted." }
\end{aligned}
$$

Example (28) is fine, i.e. mother insisted has to be a well-formed structure, and 
there is nothing else in the answer above that one would expect to render the utterance unacceptable. Furthermore, there is a very straightforward candidate in the directly preceding context that could be identified with the DNC of insist, namely: mother insisted that I do the work. On the basis of these premises and what Iten et al. say about the licensing process, we would expect the answer in (45) to be acceptable. However, it is not. To see what causes the problem in this example, compare the following question-answer pair:

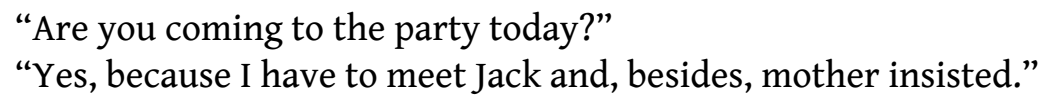

It seems that the difference between the unacceptable answer in (45) and the acceptable one in (46) is, indeed, that the latter makes sense whereas the former does not. Apparently, the DNC in structures like (28) and (46) is only allowed to pick up an antecedent from a preceding question, but not from the speaker's own answer. This way we correctly get the interpretation 'mother insisted that I come to the party', which makes sense. On the other hand, by the same rule we have to get the very same interpretation for the DNC in (45) as well, which would be incoherent: if mother insisted that I come to the party, this cannot be straightforwardly interpreted as an explanation of why the speaker is not coming to the party, as in the answer in (45).

In other words, something (presumably, the grammar of DNC in English) forces an incoherent interpretation for the answer in (45) and even blocks the selection of an appropriate antecedent for the DNC that would allow a coherent interpretation. Such cases show that the relationship between the grammar and the pragmatics component of the licensing system is more complex than what Iten et al.'s suggestion would imply. The grammar component apparently does not just generate a structure like mother insisted and leave the interpretation of the DNC to the pragmatic component. Instead, grammar can rather strongly restrict this interpretation by reference to context, thereby further limiting the role of pragmatics.

Because of the complex nature of this interaction between context and syntax, it is unclear whether all theories of grammar are equally able to formulate the relevant generalisations. Arguably a strongly "context sensitive" syntactic theory like dynamic syntax (Cann et al. 2005) would be a more promising framework to describe such phenomena than a more standard generative model.

To turn to a different issue, it seems to us that even though pragmatics is not capable of explaining all aspects of implicit arguments, it does play an extremely important role in the process of an obligatorily transitive verb becoming an optionally intransitive verb. We are referring to cases like certain intransitive uses of the verb draw, used (in special contexts) to express things like 'draw a card', 'draw a gun', etc. It seems that when a verb very frequently and predictably takes a certain kind of argument in a certain kind of situation (like draw taking a card 
as an object when the interlocutors are playing cards, or taking a gun as object in a Western movie context), it can occasionally be used intransitively. This intransitive use can eventually become lexicalised, as a sort of "technical term" used in appropriate contexts. Although this seems to be a very common and systematic phenomenon, it has been largely ignored in the literature. Still, we can safely assume that intransitivisation in such cases is intimately connected to specific situations of communication and considerations of economy, and can therefore be regarded as belonging to pragmatics. However, this conjecture will have to be confirmed by research, and the actual extent of the phenomenon in everyday language use also remains to be established.

SOURCES OF LINGUISTIC MATERIAL USED

(Examples for which we have not specified, as a source, either one of the following or one of the literature references below, are our own.)

- COSMAS: COSMAS II (Corpus Search, Management and Analysis System), Mannheim: Institut für Deutsche Sprache.

http://www.ids-mannheim.de/cosmas2/

- DUW 4: Duden Universalwörterbuch. $4^{\text {th }}$ Edition. Mannheim: Bibliographisches Institut and Brockhaus, 2001.

- LDOCE 4 CD-ROM: Longman's Dictionary of Contemporary English. $4^{\text {th }}$ Edition, CD-ROM edition. Harlow: Pearson Education, 2003.

REFERENCES

Bibok, K. and Németh T., E. 2001. How the lexicon and context interact in the meaning construction of utterances. In E. Németh T. and K. Bibok (eds.), Pragmatics and the flexibility of word meaning, pages 289-320, Amsterdam: Elsevier.

Cann, R., Kempson, R. and Marten, L. 2005. The dynamics of language: An introduction. Syntax and Semantics 35, Amsterdam: Elsevier.

Carston, R. 2002. Thoughts and utterances. Oxford: Blackwell.

Cote, S. 1997. Grammatical and discourse properties of null arguments in English. Ph. D.thesis, University of Pennsylvania.

Fillmore, C. 1986. Pragmatically controlled zero anaphora. Proceedings of the Berkeley Linguistics Society 12, 95-107.

Fodor, J. and Fodor, J. D. 1980. Functional structure, quantifiers, and meaning postulates. Linguistic Inquiry 11, 759-769. 
Goldberg, A. 2001. Patient arguments of causative verbs can be omitted: the role of information structure in argument distribution. Language Sciences 23, 503-524.

Groefsema, M. 1995. Understood arguments: A semantic/pragmatic approach. Lingua 96, 139-161.

Iten, C., Junker, M.-O., Pyke, A., Stainton, R. and Wearing, C. 2005. Null Complements: Licensed by Syntax or by Semantics-Pragmatics? In M.-O. Junker, M. McGinnis and Y. Roberge (eds.), Proceedings of the 2004 Canadian Linguistics Association Annual Conference, ACL.

Kiss, K. 2006. Focussing as predication. In V. Molnár and S. Winkler (eds.), The Architecture of Focus, pages 169-196, Berlin: Mouton de Gruyter.

Müller, S. 2002. Complex predicates: Verbal complexes, resultative constructions, and particle verbs in German. Stanford: CSLI.

Németh T., E. 2000a. Occurrence and identification of implicit arguments in Hungarian. Journal of Pragmatics 32, 1657-1683.

Németh T., E. 2000b. Implicit argumentumok a magyarban: előfordulásuk módjai és azonosításuk lehetőségei (Implicit arguments in Hungarian: Modes of their occurrence and possibilities of their identification). In I. Kenesei (ed.), Igei vonzatszerkezetek a magyarban (Verb complement structures in Hungarian), pages 197-252, Budapest: Osiris.

Németh T., E. 2001. Implicit arguments in Hungarian: manners of their occurrence and possibilities of their identification. In I. Kenesei (ed.), The syntax and semantics of argument structure, pages 113-156, Budapest: Akadémiai.

Németh T., E. and Bibok, K. 1999. Implicit arguments in Hungarian. In J. Verschueren (ed.), Pragmatics in 1998. Selected papers from the 6th International Pragmatics Conference, volume 2, pages 412-426, Antwerp: IPrA.

Postal, P. 1974. On Raising. Cambridge: MIT Press.

Rothstein, S. 2004. Structuring events: A study in the semantics of lexical aspect. Oxford: Blackwell.

Sæbø, K. J. 1996. Anaphoric Presuppositions and Zero Anaphora. Linguistics and Philosophy 19, 187-209.

Tenny, C. 1994. Aspectual roles and the syntax-semantics interface. Dordrecht: Kluwer. 
Velasco, D. and Muñoz, C. 2002. Understood objects in Functional Grammar. Working Papers in Functional Grammar 76. Amsterdam: University of Amsterdam.

AUTHOR CONTACT INFORMATION

Gergely Pethő

University of Debrecen

Institute of German Studies

H-4010 Debrecen, Pf. 47

Hungary

pethog@inf.unideb.hu

Eva Kardos

University of Debrecen

Institute of English and American Studies

H-4010 Debrecen, Pf. 73

Hungary

evikardos@t-online.hu 